\title{
Ecos de la lírica política de Rubén Darío en algunos poemas de Juan Felipe Toruño
}

\author{
Rhina Toruño-Haensly \\ The University of Texas of the Permian Basin \\ drtoruno@yahoo.com
}

\section{Resumen}

Este artículo pone sobre la palestra los hechos históricos como un continuum inspirando la creación literaria. La autora leyendo la vida de Rubén Darío, constata que la guerra hispanoamericana de 1898 conmovió profundamente a este célebre literato. En sus artículos de El tiempo, Darío censuró acremente a los Estados Unidos: "No, no puedo, no quiero estar de parte de esos búfalos de dientes de plata. Son enemigos míos, son los aborrecedores de la sangre latina."

Palabras claves: Literatura, historia, traición, política, poesía, guerra.

\begin{abstract}
This article brings forward the historical facts as a continuum that inspired a literary creation. When Reading Rubén Darío's life, the author was able to prove that the Hispano-American war of 1898 profoundly moved this remarkable writer. On the newspaper EL TIEMPO articles, Darío bitterly censured the United States: "No, I can't; I don't want to be on the side of those silver-toothed buffalos (a metaphor to describe them as barbaric and greedy). They are my enemies; they are the Latin American blood haters."
\end{abstract}

Key words: Literature, history, betrayal, politics, poetry, war.

Es interesante constatar cómo los hechos históricos continúan inspirando la creación literaria. Leyendo la vida de Rubén Darío, noto que la guerra hispanoamericana de 1898 lo conmovió profundamente. En sus artículos de El tiempo censuró acremente a los Estados Unidos: "No, no puedo, no quiero estar de parte de esos búfalos de dientes de plata. Son enemigos míos, son los aborrecedores de la sangre latina". ${ }^{1}$

1 Ernesto Mejía Sánchez, Rubén Dario: Poesía (Caracas: Ayacucho, 1977) 526. Prólogo: Ángel Rama, cronología: Julio Valle-Castillo. En adelante, cuando me refiera a este libro diré Darío: Poesía. 
Algunos años después, Darío hace referencia a la política antiyanqui en el prólogo de su poemario Cantos de vida y esperanza (1905): "Si en estos cantos hay política, es porque aparece universal. Y si encontráis versos a un presidente es porque son un clamor continental. Mañana podremos ser yanquis (y es lo más probable); de todas maneras, mi protesta queda escrita sobre las alas de los inmaculados cisnes, tan ilustres como Júpiter" (Dario: Poesía, 248). El poema al que se refiere es "A Roosevelt"; fue publicado apenas siete años después de la guerra entre España y los Estados Unidos, en que el país norteamericano tomó posesión de Cuba y de Puerto Rico.

A raíz de lo anterior los latinoamericanos consideraron a los Estados Unidos como un país invasor, que se quería apoderar de todo el continente latinoamericano. De ese temor surgió un sentimiento antiyanqui. Los poetas visionarios de sus destinos nacionalistas, con los pies y el corazón en su terruño, expresaron su temor. Podemos ver que Rubén Darío, con su poema "A Roosevelt”, simbolizó al país en la persona del presidente del país, en una forma de metonimia (persona por país):

\author{
Eres los Estados Unidos, \\ eres el futuro invasor \\ de la América ingenua que tiene sangre indígena, \\ que aun reza a Jesucristo y aun habla en español. (Dario: Poesía, 255.)
}

El temor de Darío de que los Estados Unidos invadiera cualquier país de América Latina se cristalizó en su país natal, Nicaragua, en 1910, seis años antes de que muriese el fundador del modernismo hispanoamericano. Fue a raíz del estallido en la costa atlántica de la revolución conservadora (1909) que, acaudillada por el general Juan José Estrada, derrocó a José Santos Zelaya, ${ }^{2}$ quien dejó la presidencia.

Después de Zelaya, por elección popular le sucedió el Dr. José Madriz (Dario: Poesía, 543), bajo cuyo régimen, de nuevo en la costa atlántica, la revolución conservadora triunfó (apoyada por los Estados Unidos) e hizo caer al Dr. José Madriz; Juan José Estrada asumió la presidencia. En seguida los Estados Unidos intervinieron bajo los "Pactos Dawson" "con el pretexto de prevenir el bombardeo de Bluefields y de proteger la vida y bienes de los norteamericanos" (Dario: Poesía, 545). En 1912 de nuevo los Estados Unidos invadió militarmente a Nicaragua, "con ocupación permanente y administración de las aduanas, el ferrocarril y la banca hasta 1925. Estrada reconoce ante el New York Times haber recibido un millón de dólares para el alzamiento contra Zelaya, por parte de compañías norteamericanas" (Dario: Poesía, 547).

2 General José Santos Zelaya, fue un presidente liberal de origen leonés. Fue reelecto cuatro veces y en 1907 negó la autorización para la construcción de la base naval norteamericana en el golfo de Fonseca. 
Juan Felipe Toruño, por su respeto a la soberanía de los pueblos, y especialmente a la de su país, reaccionó en forma muy tajante contra la invasión a su querida Nicaragua. Primero, se opuso a aprender la lengua inglesa (decisión que posteriormente lamentó, pues se autoeducó en las lenguas francesa y portuguesa). Segundo, aún siendo adolescente, se alistó en el Ejército para defender el gobierno constitucional de Madriz, quien no gozó del apoyo de los Estados Unidos y fue derrocado. En su novela El silencio $(1938)^{3}$ recrea al abuelo Evaristo Meneses, del héroe Oscar Cruz; aquél huye a esconderse por haber participado en el atentado para asesinar al presidente de la Republica. "Habíase descubierto el atentado contra el Presidente de la Republica, del cual él era uno de los principales factores." (El silencio, 20.) El nombre del personaje es ficticio, pero su función corresponde a la historia de Nicaragua, pues existió ese atentado contra el general Juan José Estrada.

Así como la guerra de1898 en España inspiró algunas poesías de Rubén Darío, en forma similar la ocupación norteamericana en Nicaragua motivó la poesía de Juan Felipe Toruño, quien con su soneto "Las XI de la mañana" forma parte del poema "Horario Sentimental", donde desfilan todas las horas del día. Se encuentra en el poemario Senderos espirituales (1922), en cuya introducción Toruño expone que él tejió el poema bajo el influjo de la vieja ciudad y mientras escribía "un grupo de soldados yanquis atraviesa frente la puerta de mi cuarto". ${ }^{4}$ El soneto es un grito de protesta, de coraje, al observar a su pueblo viviendo bajo una intervención extranjera como era la norteamericana, desde 1910 hasta 1925. El verso del primer terceto se refiere a esa ocupación: "Y un soldado yanqui vestido de pus pasa". Posteriormente Toruño, en su libro Poesía y poetas de América ${ }^{5}$ explicó cómo en la metáfora del color "pus" él quiso expresar la ignominia, la repugnancia, que se sentía al ver al extranjero ocupando su ciudad: "En vez de decir vestido de kaki dijo de pus. Y de pus, precisamente, porque la pus es repugnante y en aquella época de la penetración marinera estadounidense, el soldado de la ocupación repugnaba" (273).

Pienso que el hecho de contemplar a su país humillado bajo la ocupación americana motivó la redacción de ese soneto más que la influencia del poema dariano "A Roosevelt".

Paso a continuación a mostrar la influencia de la estética modernista dariana en la poética de Toruño. Darío murió en 1916 en León, Nicaragua. En esa misma ciudad nació Toruño, el primero de mayo de 1898. Él asistió a los funerales de Darío. Ya para ese entonces Toruño estaba marcado por la estética modernista, tanto de los primeros poemas darianos como por los últimos de Cantos de vida y esperanza (1905). Toruño comenzó a escribir poesía desde muy joven, pero no se ha conservado nada de ella; posiblemente se debió a que abandonó Nicaragua

3 El silencio (San Salvador: Editorial Arévalo, 1935). Obtuvo el primer premio en el concurso del "Libro Americano" celebrado en Matanzas, Cuba en 1938.

4 Juan Felipe Toruño, Senderos espirituales. León, Nicaragua: Tipografía La Prensa, 1922, 9.

5 Poesía y poetas de América: Trayecto en ámbitos, fisonomías y posiciones (San Salvador: Imprenta Funes, 1945) 273. 
en 1923. Su dedicación a las letras no se registra hasta en abril de 1918 cuando se inició en el periodismo Eco Nacional, al publicar algunos artículos y noticias. ${ }^{6}$ De acuerdo con el Dr. Jorge Eduardo Arrellano en su libro Literatura Nicaragüense, los jóvenes postmodernistas se agrupaban en torno de ese diario:

Varios trabajaban en su redacción acogidos por el eminente escritor Mariano Barreto, quien había comprado el diario a su fundador: José Constantino González. Y de todos ellos, Juan Felipe Toruño (1898-1980), poseía una envidiable disciplina intelectual; por eso el año siguiente recibía la dirección del diario y fundaba la revista Darío. El título de este órgano reveló la vinculación modernista de esos muchachos que sumaron veintidós según el mismo Toruño.?

El primer poemario de Toruño, Senderos espirituales (1922), lo escribió bajo la influencia de Darío. En el preámbulo titulado “Al tropezar” dice:

El primer libro: más que todo encontraréis sinceridad en esta obra. $\mathrm{He}$ querido adaptarme al concepto de Darío: "Ser sincero es ser potente". Mis versos van desnudos en los parajes de la poesía contemporánea: árboles silenciosos y pensativos que se enfilan en las sendas espirituales. Minas interiores: oro y azul de una intención única, me indican por donde volar debe mi psiquis... El hombre me ha enseñado mucho: libro abierto en el que he aprendido el sistema del equilibrio material. Lo demás ha venido en mí... La armonía de lo visible me subyuga, la armonía de lo invisible me atrae. Y, con esa fiebre de misterio, he sabido leer, en el intrincado alfabeto del espacio, el lumínico silencio de las estrellas. ${ }^{4}$

La influencia de Rubén Darío y del modernismo es innegable en Nicaragua, en España, en México y en general en toda la América Latina, como bien señaló el famoso escritor argentino Jorge Luis Borges, quien argumenta que todos los poetas en América Latina, incluso él, comienzan bajo la influencia de Darío. Así Toruño "como poeta, surge modernista y luego se esfuerza por asimilar sustancias vanguardistas". ${ }^{8}$ Toruño después se independiza, al igual que Neruda, Borges, Octavio Paz y otros grandes poetas de su tiempo. Se convierte en poeta vanguardista, romántico, místico, metafísico y cósmico.

El poema "Mensaje a los hombres de América" (1939) presenta características modernistas y vanguardistas por varias razones: fue escrito en versos libres, hay

6 José Jirón Terán, poeta compatriota y amigo personal de Toruño, es un distinguido daríista, reconocido mundialmente, que ha hecho una labor encomiable de organizar una biblioteca de literatura nicaragüiense en su ciudad de origen, León. El entrevistó a Toruño, quien le proporcionó muchos datos biográficos y con ellos redactó el mejor estudio que hasta la fecha se tiene sobre la vida y obra de Toruño. "Juan Felipe Toruño en sus cincuenta años de periodismo y actividades literarias: 1918-1968" (León, Nicaragua: Biblioteca "José Jirón”, 1994) 3. Es un texto de 119 páginas, mecanografiado por José Jirón Terán y revisado por Juan Felipe Toruño.

7 Jorge Eduardo Arellano, Literatura nicaragüense (Managua: Distribuidora Cultural, 1997) 53.

8 David Escobar Galindo, Índice antológico de la poesía salvadoreña, 2. ${ }^{a}$ ed. (San Salvador: UCA Editores, 1987) 306-7. 


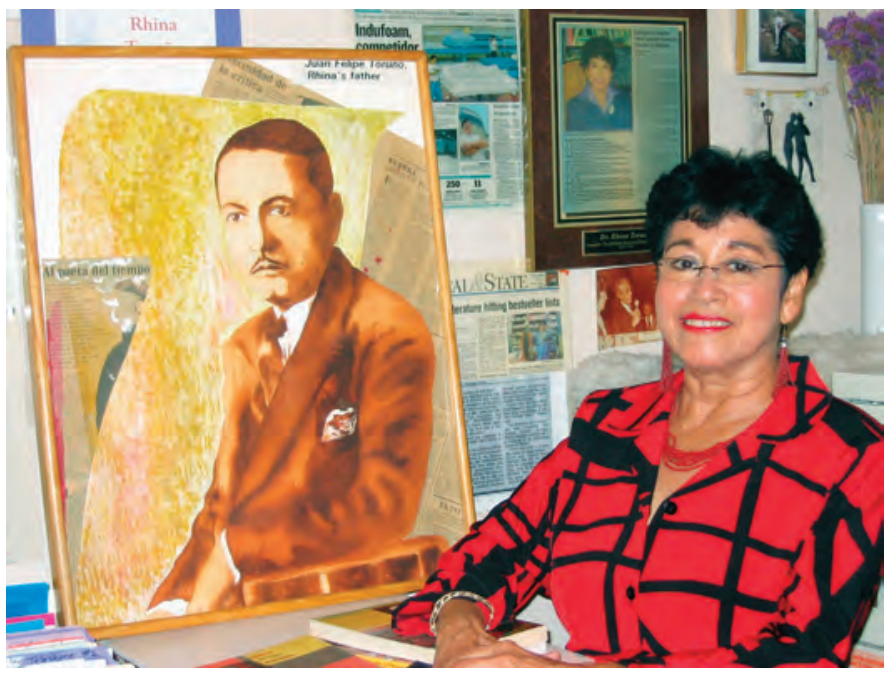

Dra. Rhina Toruño-Haensly

experimentación del lenguaje, hay referencias a la mitología clásica, y muestra la pureza del lenguaje, la sonoridad, la sensualidad, la rima y la musicalidad. ${ }^{9}$ Es un poema cósmico porque se refiere a todo el universo.

Yo agregaría "indígenista-cósmico", dado que se refiere en gran parte y con rasgos positivos a nuestros antepasados, nuestros caciques indios. En el poema hay alusiones a los caciques desde el Valle del Anáhuac hasta los del Cono Sur, y continúa con los elementos vitales del universo: el agua, el aire, el fuego, la tierra, citados por primera vez por los presocráticos. Hay en este poema una referencia universal, la cual no es solo a nivel geográfico, sino también a niveles cultural, espiritual, esotérico y místico, cuando dice: " $i A$ vosotros hablo constituidos en guión que se extiende entre la cultura de hoy y la cultura del mañana!" (versos 13-14).

El poema también expresa la unión conflictiva del hombre con su entorno y con su terruño cuando el yo poético pide a los hombres que miren, que piensen, que escuchen los gritos angustiosos de su "madre tierra". Es importante mencionar que Toruño consideró que para los nicaragüenses siempre está presente la "madre tierra" en su lírica o narrativa. La dedicatoria de Senderos espirituales apunta lo siguiente: "A los que conmigo van a la sagrada selva". También hay que recordar que a la edad de 14 años Toruño pernoctó en la selva nicaragüense por seis meses. Ya adulto ingresó a la francmasonería, donde se acostumbra a disciplinar el espíritu, dominar el cuerpo y aprender a escuchar los sonidos de la madre naturaleza, como también a interpretar sus signos y símbolos.

9 "Mensaje a los hombres de América," Hacia el Sol (San Salvador: Imprenta Funes, 1940) 4346. También se reproduce en Raiz y sombra del futuro (San Salvador: Imprenta Funes, 1944) 37-39. 
"Mensaje a los hombres de América" es un mensaje, un llamado patriótico a todos los americanos, sean del norte, centro o sur del continente americano:

La estructura externa del poema presenta 82 versos en estilo libre, agrupados en cinco estrofas y tres pares de versos dísticos. En cuanto a la estructura interna, vemos que los primeros 29 describen el mundo en forma caótica, lleno de violencia, odio y muerte de "caínes modernos". El hablante lírico llama a esta situación desesperante de "tremendo bestial cataclismo" (verso 9).

El mundo entre ígneas tormentas envenénase.

Estalla en famélicos odios.

Caines modernos. Brutos sanguinarios, asesinan, traicionan.

No fulgen aurorse do redención ni de paz.

Tempestuosas pasiones trituran los dorsos del globo.

Millones de arpías destrozan alturas excelsas.

Perece la armonía. ; Y no hay comprensión!

¡Y no hay concilianción! ; Y ha muerto el Amor!

Ante este tremendo bestíal cataclismo, ¿qué hacemos?

¿Qué hacemos los hombres habiendo ídeales lumínicos

conciencia de espiritu, miel en el alma

y fuegos angélicos en el corazón? (Versos 1-12).

Esta primera estrofa es un oxímoron, dado que une dos opuestos: "los caínes modernos (verso 3) y los hombres con fuegos angélicos en el corazón" (verso 12). En ese entonces la madre patria estaba sangrando bajo la guerra fascista, llamada "Guerra Civil Española". Dos años antes los poetas vanguardistas, de tendencia izquierdista, latinoamericanos acudieron a España para protestar contra el fascismo, entre ellos estaban Pablo Neruda, Cesar Vallejo con su poema "España, aparta de mí este cáliz", y Octavio Paz con su poema "No pasarán". Se estaba iniciando la Segunda Guerra Mundial. El Salvador (donde vivía Toruño) estaba bajo una dictadura opresora, como era la del general Maximiliano Hernández Martínez (1931-1944).

Toruño había vivido en carne propia la invasión norteamericana en su país natal y temía una nueva invasión en Centroamérica. Por lo tanto, a traves de la lírica, pide a los hombres, pero a aquellos que puedan reflexionar en medio de una guerra, que hagan algo para impedir la destrucción del ente humano.

El tono es mesiánico y apocalíptico, con implícitas referencias a los cuatro caballos del Apocalipsis (Apocalipsis, capítulo 6:1-9). En los versos a continuación, sentimos que es la voz del trueno la que habla, la del profetapoeta que denuncia el desasosiego que hay entre los humanos:

¡Vivimos la hora repugnada que desoye la voz del criterio. . .!

La razón del sistema infernal, la lógica de la dinamita, 
El argumento omnímodo de la destrucción y de la matanza, imponen sus materiales exterminadores. (Versos 26-29.)

El yo poético está pidiendo a todos los Hombres de América, en mayúscula y en tono imperativo, que escuchen, que actúen para eliminar las guerras, los odios, el hambre, la muerte entre los americanos, y construir un mundo unido de amor y de paz.

Después de estos 29 versos hay un cambio drástico a nivel del contenido y de la forma. A partir del verso 30 el pronombre personal vosotros se cambia por "nosotros". El mensaje sigue dirigiéndose a los hombres de América, pero, a partir de este verso, la responsabilidad es compartida: somos todos nosotros los hombres de América.

Pero ¿quiénes somos los hombres de América? La respuesta se encuentra no solo en un tono mesiánico, sino que tambien queda expresada en una metáfora espiritual, refiriéndose al hombre como especie, no como individuo; por lo tanto, el tiempo cronológico está en suspenso. El verbo es usado en presente perfecto, implicando que los latinoamericanos del siglo XXI hemos visto pasar ante nuestros ojos más de quinientos años de historia de guerras y odios contra nuestros antepasados. El hablante lírico se refiere a la época precolombina y al momento de la conquista de América por los españoles al mencionar a los diferentes caciques:

Nosotros, los hombres de América,

los que vimos pasar con su bosque de flechas a Manco Capac,

y cargando simbólico tronco de árbol a Caupolicán,

y sufrir y luchar a Lempira y a Urraca,

a Tecúm Umán, a Atlacalt y a Nicarao Cali. (versos 29-33)

[..........................

los que somos hermanos por carne y espiritu

los que tenemos visión de lo que es y será nuestra América

responsabilicémonos.

Aportemos la idea y el alma y la lealtad en la tarea magna:

COMPRENDAMOS (Versos 41-45).

El llamado a los hombres de América no es para todos los americanos desde Alaska hasta el Cabo de Hornos, sino para los que cumplan con los requisitos de ser "hermanos de carne y de espíritu", o sea, los amerindios o latinoamericanos: mestizos, indios, negros y blancos. Para los otros los requisitos son los de tener la visión, el ansia, el coraje de querer convertir la América india en la América líder, la que posee valores éticos y culturales que orgullosamente vienen desde sus antepasados luchadores y gloriosos. 
Este poema es también un canto de alabanza a las grandezas de la América precolombina y una invitación al compromiso, dado que en ese entonces había guerra en Europa. Primero estalló en 1936, con la Guerra Civil Española, y después se extendió por toda Europa:

\section{La América habrá de fijar su cultura perfecta, imprescindible, universal. \\ La América nueva que viene creciendo en los siglos! (46-48)}

El hablante lírico se refiere a una América que sigue creciendo desde hace 25 siglos. Es polisémico el término nueva, El primer significado se encuentra en los versos 53-55 donde el hablante lírico comenta que "habló con el fuego, el agua y el viento", sugiriendo que la América nueva tiene, en su ontogénesis, la civilización occidental. El fuego, el agua y el viento constituyen una referencia a los elementos vitales discutidos por los presocráticos de la escuela Jónica en el siglo $\mathrm{V}$ antes de Jesucristo, cuando se preguntaban de dónde viene la vida. Tales de Mileto respondía que viene del agua, dado que él vivía en la isla de Mileto, rodeado de agua; además reflexionaba que el animal y el hombre se gestan por medio del semen, el cual es líquido.

También el agua, afirmaban los presocráticos, constituye el elemento vital en los vegetales, lo cual lo comprobaban cuando al triturar una hoja les quedaban húmedos los dedos. Anaxímenes, también de Mileto, respondía que el origen de todo estaba en el aire. Esta idea, modificada, fue apropiada por las religiones cristianas al explicar que Dios engendró la vida en el hombre a través del soplo divino, que en resumidas cuentas es el aire.

Juan Felipe Toruño, poseedor del conocimiento de las culturas clásicas, orientales y esotéricas, compara el origen de la América indígena con aquellos tiempos inmemoriales en los cuales los pensadores de las escuelas jónicas buscaban el origen de la vida y de las cosas.

Un sentido de la "América nueva" es la fusión de razas que se efectuó cuando la princesa Malitzin (Malinche) fue obsequiada juntamente con diez vírgenes más al invasor español Hernán Cortés; y él se acostó con Malitzin. De esa unión nació el primer mestizo, Martín.

Otro significado de la América hispana es que tiene una cultura viva y se mantiene en la búsqueda incesante de la verdad; la América Latina es filósofa; es luchadora, es maestra que enseña y enseñará a las nuevas generaciones los valores universales. De acuerdo con el poema "Mensaje a hombres de América", ahora es el turno de la América Latina de convertirse en líder en el contexto de todas las naciones del mundo; y lo será por practicar los valores eternos cristianos o los de la mayoría de las religiones y sociedades filantrópicas que son capaces de inculcar la armonía y la unidad entre todos y todas a través del amor, la paz y el mutuo perdón. 
El poema se aproxima al final con la alusión directa a un Cristo vivo, no una estatua como El Corcovado que se encuentra en Río de Janeiro. Esto es connotado por el uso del participio presente que funciona como adjetivo: "Y el Cristo indicando las rutas desde las expectantes cumbres de los Andes" (versos 73-74). El Cristo de los cristianos también es respetado y considerado un profeta dentro de la francmasonería.

La estrofa final es un himno de amor, de alegría, de paz, de resurrección cristiana o ética masónica; es una nueva oda de la alegría o de la amistad de Beethoven expresada en versos y con el referente externo americano:

Y la humanidad que quepa en América, pueblo de pueblos luchadores, trabajadores, soñadores

Y la paz tenga asilo en el alma del pueblo titánico,

y fije en los siglos esa alma sagrada. .

$$
\text { - ¡Así sea! (versos 75-79) }
$$

El uso continuo de vocales fuertes y de las consonantes $r$ y $s$ dan un ritmo marcial, pletórico de vida, energía, alegría. Y la expresión final del poema alude al final de una plegaria: “-¡Así sea!”. El poeta dice Mario Vargas Llosa se convierte en un deicida, aunque en este caso el yo poético reconoce la supremacía de Cristo y le deja que Él indique a la América joven el camino que debe seguir.

Al cerrar el poema con el "ASÍ SEA", el yo poético invita al lector a ser cómplice con él, a que se responsabilice (véase verso 43: responsabilicémonos) en la tarea inminente de llevar a la práctica la Unión Panamericana. Es importante recordar que este poema se escribió en 1939; aún cuando ya estaba fundada la Unión Panamericana se discutía mucho en los periódicos y revistas sobre cómo darle vitalidad. Si el poema se lee como testimonio de un teósofo (Toruño lo era) o como un manifiesto de los unionistas panamericanos, el deseo o propósito que posiblemente inspirara al cómplice lector era llevar a la práctica lo que había leído.

Parte del título de este ensayo se refiere a la estética modernista de Rubén Darío en la poesía de Toruño. Leamos con atención los siguientes versos del poema "Mensaje a los hombres de América:"

¡Hombres de América!: Oíd los vocablos angustiosos

Que, amargos nos llegan del caos insólito.

Mirad la sangre que mana de las arterias de la tierra. (Versos: 16-18.)

En estos versos es evidente la existencia del eco dariano cuando el bardo nicaragüense Toruño se refiere a la tierra como el vientre materno. El profesor argentino Francisco Propato comparó la poesía de Toruño con la de Darío de la siguiente forma: 
Si Nicaragua dio al universo americano su máxima lírica con Rubén Darío, San Salvador ostenta con legítima ufanía en su Parnaso a un poeta de fuertes características propias y cantor excelso de la patria grande, que es la América toda, la que va de polo a polo, sin odios raciales. ... "Mensaje a los hombres de América" dirá al culto lector cual es la envergadura moralespiritual y la capacidad intelectiva del eximio vate salvadoreño. Por ese "Mensaje" podemos aquilatar el don extraordinario que posee Juan Felipe Toruño para interpretar, con cálido acento y armoniosos versos, el alma noble y generosa de nuestros pueblos, los que no defraudarán la esperanza que la humanidad ha depositado en ellos. . . (Poemas Andantes, 12)

Se puede ver que tal apreciación no provenía de un amigo o conocido de Toruño, dado que le confunde la nacionalidad. Toruño amó entrañablemente a El Salvador, vivió en ese país desde la edad de 25 años hasta los 82 cuando murió, nunca lo abandonó. Le dedicó poemas y cuentos en De dos tierras: León y San Salvador (1947), ${ }^{10}$ pero nunca renunció a su nacionalidad nicaragüense.

Como ya lo he señalado, el poeta leonés Toruño incursionó desde su adolescencia en la poesía, sin embargo, es hasta los 18 años que se publica su poesía. A la edad de 20 años (1918) fundó la revista Darío, que brindaba la oportunidad a jóvenes y no jóvenes de expresar sus ideas. La primera revista en honor al epónimo fundador del Modernismo. Después de tres años dejó Nicaragua y se instaló en El Salvador. Allí continuó su actividad poética y también política bajo una forma diferente, dado que vivía en el extranjero, específicamente en El Salvador.

El consideró que su forma de lucha contra la injusticia social que sufría su país adoptivo fue la de promover un pensamiento crítico, hacer reflexionar a los jóvenes poetas sobre las causas que generan la opresión de los pueblos. Manlio Argueta, en su artículo "Juan Felipe Toruño y los 'Sábados de Diario Latino': un ave en la tempestad", ${ }^{11}$ se enfoca en el papel que desempeñó Toruño como promotor de los jóvenes que llegaron a constituir grupos de varias generaciones de escritores en el suplemento literario del Diario Latino.

10 Libro de cuentos en el que se encuentran paisajes, leyendas, tradiciones y nombres de personas importantes de ambos países. (San Salvador: Imprenta Funes, 1947).

11 Este artículo Juan Felipe Toruno, historia literaria y "Sabados de Diario Latino" por Manlio Argueta , ps. 273 - 282. Se encuentra entre los 24 ensayos que constituyen el libro de 342 páginas: Juan Felipe Toruño en dos mundos. Análisis critico de sus obras. Editoras: Doctoras Rhina Toruño y Ardis Nelson. Publicado en MA, Estados Unidos . 
Según el propio Toruño, el suplemento se comenzó a publicar en 1932, año que se conoce como el de la matanza o de la insurrección "comunista". Manlio Argueta comenta, en ese artículo, que es sobre todo el inicio de un ciclo histórico, el cual no acabó de cerrarse sino hasta después de una guerra civil de casi 15 años, con el Acuerdo de Paz firmado en enero de 1992.

Continúa Manlio diciendo que hay cierto simbolismo entre el año de fundación del suplemento y el inicio de la marginalización de las expresiones jóvenes salvadoreñas, a las que se les condenó por su posición de izquierda, lo cual originaba intolerancia hacia su obra, propio del período absolutista que duró 60 años en El Salvador.

Por extender la mano a los jóvenes rebeldes universitarios y darles la oportunidad de publicar sus ideas en un periódico que, con el correr de los tiempos, se consideró una condición sine qua non publicar en Diario Latino como paso previo a la consagración de escritor. Así lo sugiere Manlio Argueta a través del héroe Alfonso, un joven, en su novela Caperucita en la zona roja, cuando dice: "Tengo un bibliotequita, ¿cómo sabe que he comprado esos libros?, preguntó el viejo. Yo leo el suplemento literario en el periódico Diario Latino, donde ustedes publican. ¿Usted conoce a Felipe Toruño también?”. ${ }^{2}$

Es allí donde, a través de la "Página cultural", que Toruño fundó en Diario Latino en 1932, que realizó su lucha contra el absolutismo, ofreciendo su 'página' a los jóvenes: "Sábados de Diario Latino". A pesar de que en esos momentos existían gobiernos militares que mantenían un férreo control, hubo espacio siempre para la expresión literaria, independientemente de su ideología. Así, en "Sábados de Diario Latino" se promovió a Roque Dalton García, Manlio Argueta, Tirso Canales, José Roberto Cea, Oswaldo Escobar Velado, Pedro Geoffroy Rivas, Roberto Armijo, Mercedes Duran y a Antonio Gomero, que Toruño lo llamaba "el poeta salvaje"; a Mauricio de la Selva, Danilo Velado y a muchos más.

La única aristocracia que Toruño respetó y admiró fue la del talento y el trabajo arduo y honesto. Esa es la herencia espiritual, cultural que hemos recibido tanto sus hijos e hijas como el pueblo salvadoreño y el nicaragüense, a los que amó mucho. A estas dos naciones, Toruño les dedicó muchos poemas, ensayos y libros, como De dos tierras (libro de cuentos); poemas, como "San Salvador y León". Ciudad dormida, dedicada a León. Desarrollo literario de El Salvador (1957); como el titulo lo sugiere, se refiere a la historia literaria de El Salvador.

Juan Felipe Toruño, al vivir en El Salvador, como extranjero, se abstuvo de participar o representar a gobierno alguno. Cuando hizo su gira por América Latina en los años cincuenta, dio conferencias en las diversas universidades de

12 Manlio Argueta, Little red riding hood in the red light district. (Connecticut: Curbstone Press, 1998) 78. Translated by Edward Waters Hood. La traducción al español es responsabilidad mía. 
Latinoamérica, desde Costa Rica hasta Brasil, Chile y Argentina. El gobierno de El Salvador le ofreció costear el viaje si aceptaba ir en su representación, y Toruño no aceptó.

El único puesto gubernamental que aceptó en los últimos años de su vida fue el de ser agregado cultural por el gobierno de Nicaragua en El Salvador. El nunca renunció a su ciudadanía nicaragüense, ni a sus ideales de luchar por una libertad de expresión y una actitud crítica frente a los diversos gobernantes y partidos políticos; y esa fue la razón por lo cual él fundó su "Sábados de Diario Latino". Quería que los jóvenes universitarios tuviesen un vocero de sus críticas e inquietudes de justicia social.

Recuerdo muy bien, y todavía puedo escuchar la voz de mi padre cuando me comentó lo que el director de Diario Latino de los años sesenta, don Miguel Pinto, le pidió varias veces que no debería darles más cabida en el periódico a los jóvenes si no cambiaban de tono, dado que estaban escribiendo críticas muy fuertes contra el gobierno.

Este comentario fue a raíz de un artículo escrito por Mercedes Durand, quien no quiso cambiar el tono de su poesía. Juan Felipe Toruño continúo abogando por todos los jóvenes poetas porque sostenía que en una democracia debe existir el libre juego de ideas. En El Salvador, durante los años de 1960 a los 1970, era prohibido leer El Capital de Karl Marx, o los libros de Lenin o del Ché Guevara. Por eso, la actitud de Toruno fue muy valiente, arriesgando su propio trabajo al servicio de sus ideales. 


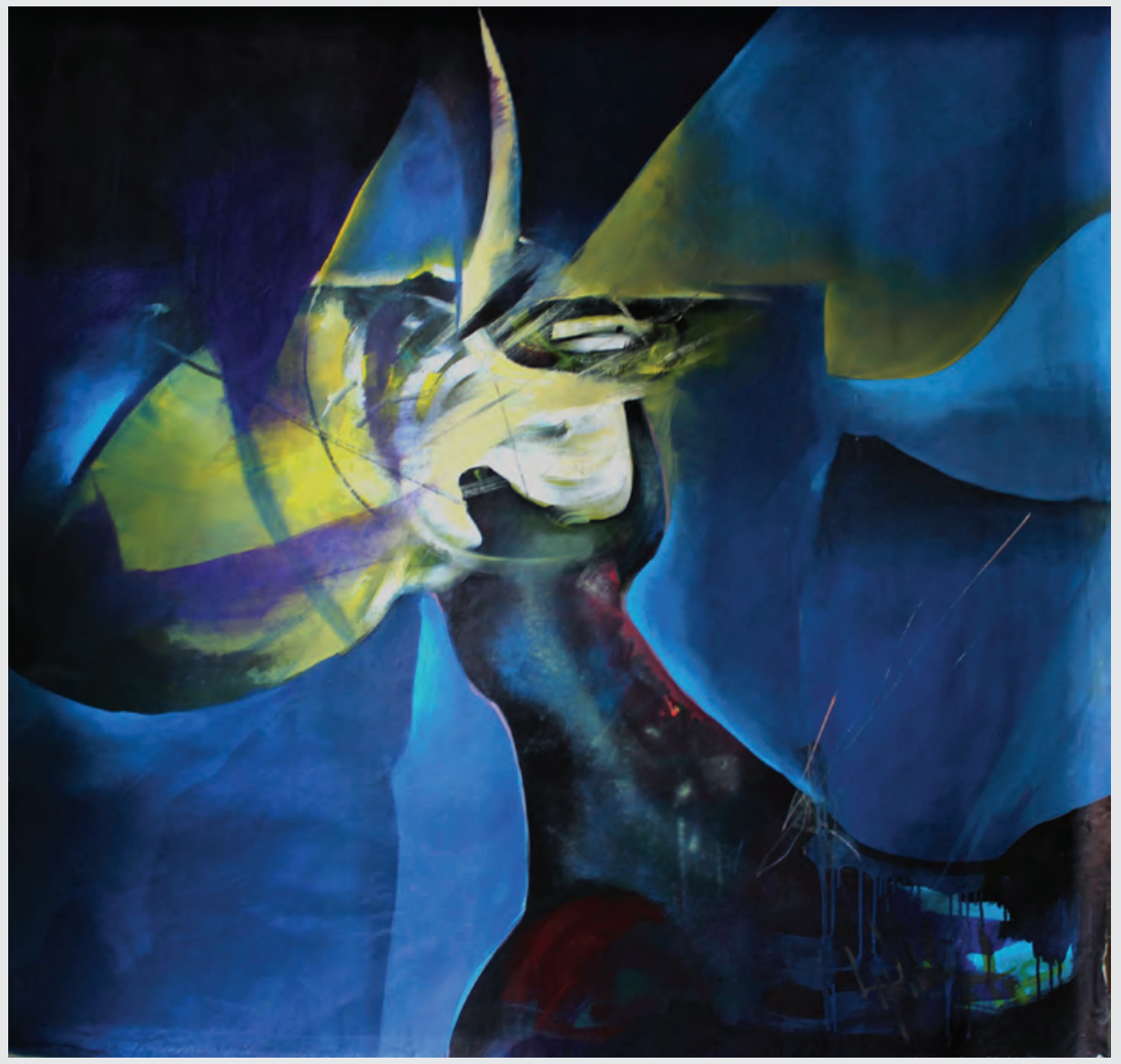

\section{"Abstración"}

Medidas: 153 x $150.5 \mathrm{cms}$

Técnica: mixta

Año: 2008 